\title{
Hospice Care at Medical Facility
}

National Cancer Institute

\section{Source}

National Cancer Institute. Hospice Care at Medical Facility. NCI Thesaurus. Code C99910.

End-of-life care which will be administered in a medical center. (ACC) 